\title{
Changes in Nanoscaled Mechanical and Rheological Properties of Asphalt Binders Caused by Aging
}

\author{
Ben Liu, Junan Shen, and Xuyan Song \\ Road Engineering Research Center, Suzhou University of Science and Technology, Suzhou 215011, China \\ Correspondence should be addressed to Junan Shen; shenjunan@hotmail.com
}

Received 28 January 2015; Accepted 30 March 2015

Academic Editor: Changhong Ke

Copyright (C) 2015 Ben Liu et al. This is an open access article distributed under the Creative Commons Attribution License, which permits unrestricted use, distribution, and reproduction in any medium, provided the original work is properly cited.

\begin{abstract}
Aging of an asphalt binder causes the changes in the microstructure and, consequently, in the nanomechanical and rheological properties of the aged asphalt binder. Short-term aging on asphalt binders was simulated using rotating thin film oven (RTFO). These changes in the microstructure and nanomechanical and rheological properties were measured using atomic force microscope (AFM) and dynamic shear rheometer (DSR). The results indicated that (1) the adhesive force of the asphalt binder from AFM tests was increased after RTFO aging; (2) $G^{*}$ of the asphalt binder from DSR tests increased after RTFO aging; (3) the results from AFM were consistent with those from DSR, explaining the mechanism of the changes of rheological properties.
\end{abstract}

\section{Introduction}

Asphalt binder plays an important role in the performance of asphalt mixture, which accounted for $29 \%$ of rut depth at high temperature, according to the strategic highway research program (SHRP) research. Rheology is a very powerful tool for characterizing and quantifying materials properties. Since the rheological properties of asphalt change during production and continue to change subsequently in service, there is necessity to study the phenomenon of aging [1]. As a result of the global climate, air temperature of most areas in China in the summer is higher and higher and lasts for a long time, making the rutting and water damage particularly more prominent than ever before. The DSR is widely used for characterizing asphalt binders and is required for specifications in many countries. DSR can accurately measure the rheological responses of asphalt films adhesion to aggregate's surfaces [2]. As a special material, asphalt binder has viscoelastic property and is more complicated than other pavement materials. The testing involves using rotating thin film oven (RTFO) aged binders to mimic the state of binder aging in the mixture beams [3]. Because of its complexity in compositions, the rheological properties of asphalt binder are dependent on the aging, the temperature tested, and the test methods. A number of studies have recognized that binders of nearly identical SHRP performance grades can show differences in fracture properties that vary significantly [4-6]. In order to understand the changes in nanoscale caused by the aging of short and long terms, the frontier of atomic force microscope (AFM) was used to explore the nanomechanical forces. The adhesion, nanoforce curve, and rheological properties were tested on an asphalt binder before and after aging through rotating thin film oven (RTFO) aging.

\section{Materials and Methods}

2.1. Materials. This research used Shell Pen 70\# as asphalt. The properties of Pen asphalt were shown in Table 1.

It is indicated from Table 1 that the asphalt conformed to the requirements of the Chinese specifications.

In addition, the materials used for atomic force microscope test including acetone solution and carbon disulfide solution are all commercially available.

2.2. Methods. AFM analysis uses BRUKER company's icon type atomic force microscope. Its principle is that there is a small tip which is very sensitive to the weak force at the other end of micro-cantilever. Tip gently contacted the sample surface, due to the extremely weak repelling force between needle tip atoms and the sample surface atoms, the force will 
TABle 1: Properties of Shell Pen 70\# asphalt.

\begin{tabular}{lcccc}
\hline Test index & Unit & Pen 70 & Specs & Test method \\
\hline Penetration $\left(25^{\circ} \mathrm{C}, 5 \mathrm{~s}, 100 \mathrm{~g}\right)$ & $0.1 \mathrm{~mm}$ & 68 & $60 \sim 80$ & T0604 \\
Ductility $\left(5 \mathrm{~cm} / \mathrm{min}, 15^{\circ} \mathrm{C}\right)$ & $\mathrm{cm}$ & $>100$ & $\geq 100$ & $\mathrm{~T} 0605$ \\
Softening point $($ global method) & ${ }^{\circ} \mathrm{C}$ & 58 & $\geq 46$ & $\mathrm{~T} 0606$ \\
Dynamic viscosity $\left(60^{\circ} \mathrm{C}\right)$ & $\mathrm{Pa} \cdot \mathrm{s}$ & 230 & & $\mathrm{~T} 0625$ \\
The residue after thin film oven & & 0.04 & $\leq \pm 0.8$ & $\mathrm{~T}$ \\
Quality loss & $\%$ & 27 & 15 & T0609 \\
Ductility $\left(5 \mathrm{~cm} / \mathrm{min}, 15^{\circ} \mathrm{C}\right)$ & $\mathrm{cm}$ & 69 & $\geq 58$ & T0605 \\
Penetration ratio $\left(25^{\circ} \mathrm{C}, 5 \mathrm{~s}, 100 \mathrm{~g}\right)$ & $\%$ & & T0604 \\
\hline
\end{tabular}
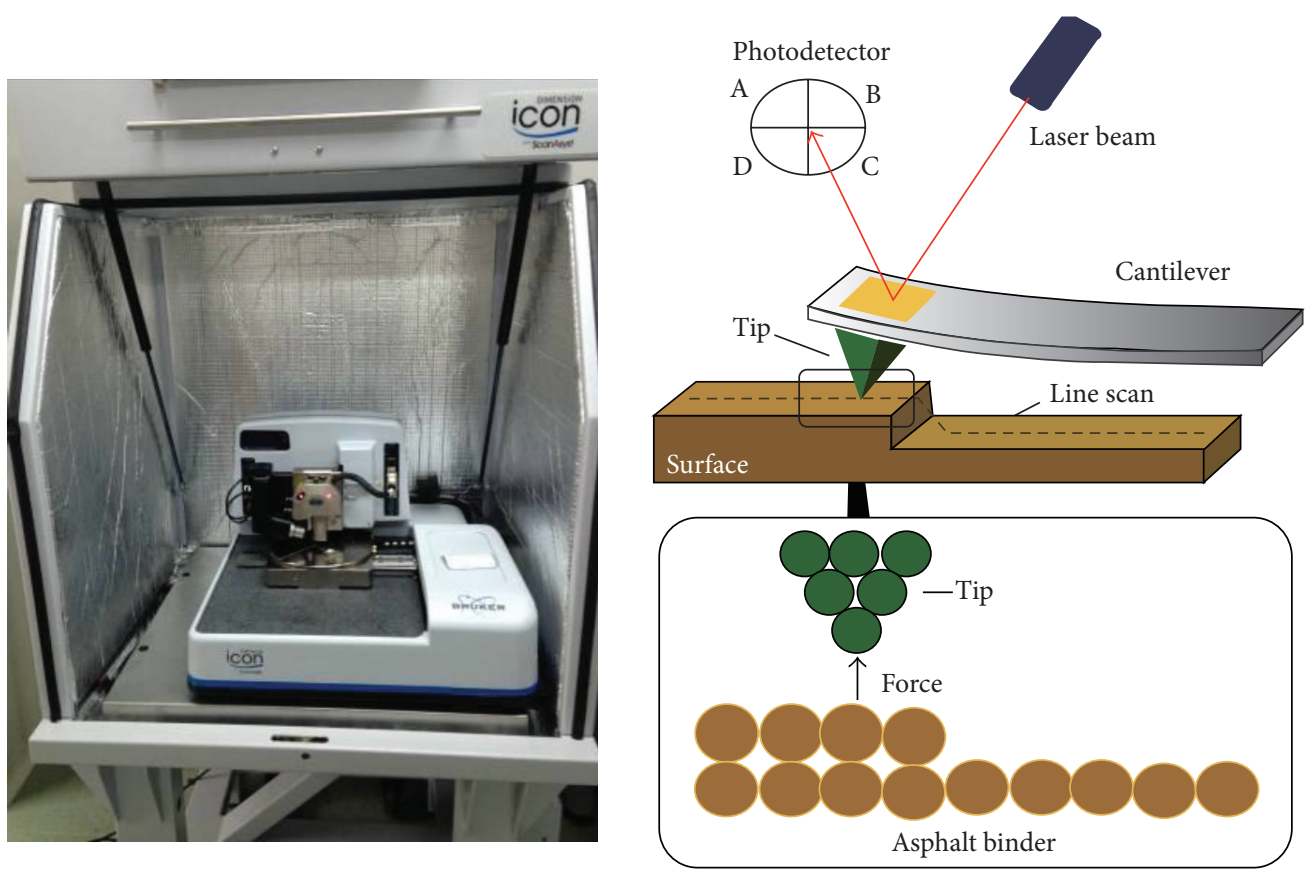

FIgure 1: Atomic force microscope used in the study.

be kept constant in the scan control. A sharp tip probes the surface of a sample while collecting data. The cantilever tip is usually only several micros in length, and is located at the free end of a cantilever. Vertical displacement and lateral distortion in the cantilever is measured and mapped as the tip probes the surface of the specimen. The surface information will be measured by nanoscaled resolution. The operation mode of the atomic force microscope was classified in the form of acting force between tip and sample classification. There are mainly three kinds of operating modes: contact mode, noncontact mode, and tapping mode, with atomic force microscope structure model as shown in Figure 1.

The nanomechanical properties of the asphalt before and after aging are conducted by contact model. The probe model of the cantilever used in the study is SCANASYST-AIR, and its elasticity coefficient is $0.4 \mathrm{~N} / \mathrm{m}$. After correction, deflection sensitivity value of the cantilever beam is $51.48 \mathrm{nN} / \mathrm{V}$, and the $K$ of the spring coefficient is $0.4840 \mathrm{~N} / \mathrm{m}$.
This study followed the steps below [7]:

(1) Weigh the asphalt before and after aging separately, with the weight ratio of carbon disulfide and asphalt $1: 9$.

(2) Wipe completely glass slide with acetone solution to remove surface dust and make sure the slide surface is clean.

(3) Absorb by glue rubber head a drop of the asphalt solution prepared and release it on a glass slide.

(4) Let the drop of solution be a thin film.

Dynamic shear rheometer (DSR) is a machine that determines the rheological properties of asphalt binders for Superpave system: rutting resistance at high temperature and fatigue resistance at intermediate temperature. It belongs to the plate type rheometer. Asphalt samples were placed between parallel plates as shown in Figure 2, at a certain rate of rotating 


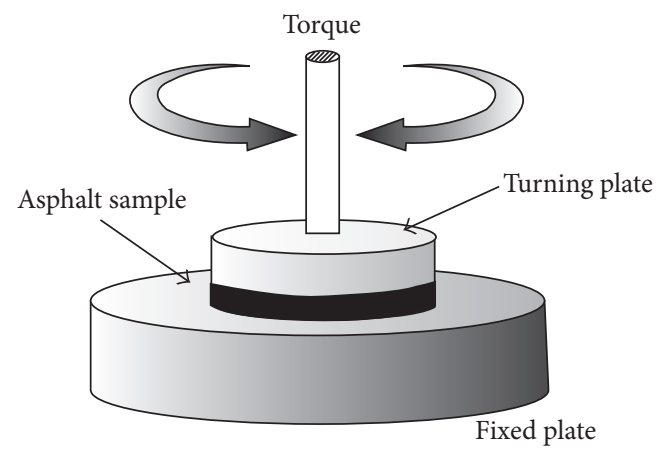

FIgURE 2: Asphalt sample loading way.

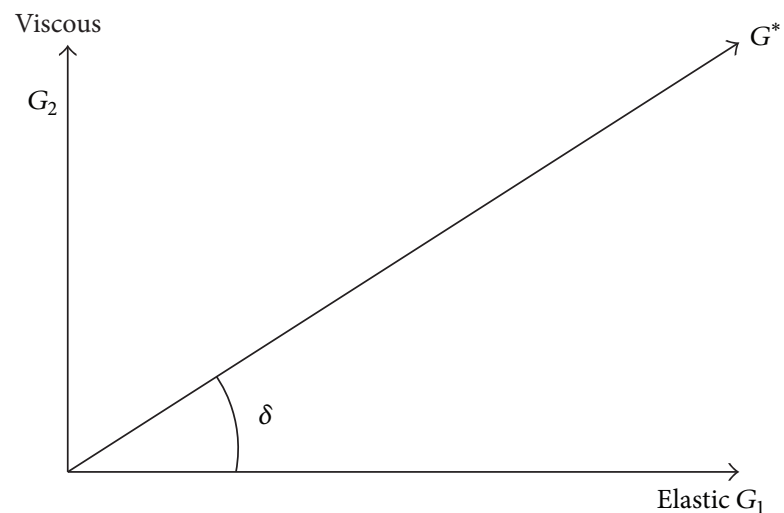

FIgURe 3: Viscoelastic complex modulus.

shearing, determining binder plural shear modulus $G^{*}$ and phase angle of the $\delta$, charactering its viscoelastic properties. $G^{*}$ is material repeated shear deformation measurement of total resistance, composed of elastic (recoverable) part of $G_{1}$ and $G_{2}$ of part of the viscosity (irreversible). The $\delta$ is elastic and viscous deformation amount of relative index. The smaller the $\delta$ is, the closer the material is in the elastomer, complex shear modulus $\left(G^{*}\right)$, and its two components: storage modulus $\left(G_{1}\right)$ and loss modulus $\left(G_{2}\right)$ [8], as shown in Figure 3.

\section{Results and Discussion}

3.1. Nanoscaled Results from AFM. Nanoscaled mechanical properties, that is, adhesion of asphalt binders before and after RTFO, were studied by using AFM. Nanoadhesion and nanoforce were measured, respectively [9]. AFM test probe of the elastic coefficient of cantilever beam is $0.4 \mathrm{~N} / \mathrm{m}$ and correction of the cantilever beam of $K$ value was $0.4840 \mathrm{~N} / \mathrm{m}$, with sweeping range of 20 microns $\times 20$ microns. The results of the nanoadhesion and nanoforce of the asphalt before and after RTFO aging are shown in Figures 4-7, respectively.

Figures 4 and 5 are the results of nanoadhesion taken for asphalt before and after aging. These figures showed the nanoadhesion distribution on the area of asphalt of 20 microns $\times 20$ microns. The darker the color, the smaller the adhesion. It is clear that the dark area was smaller and light

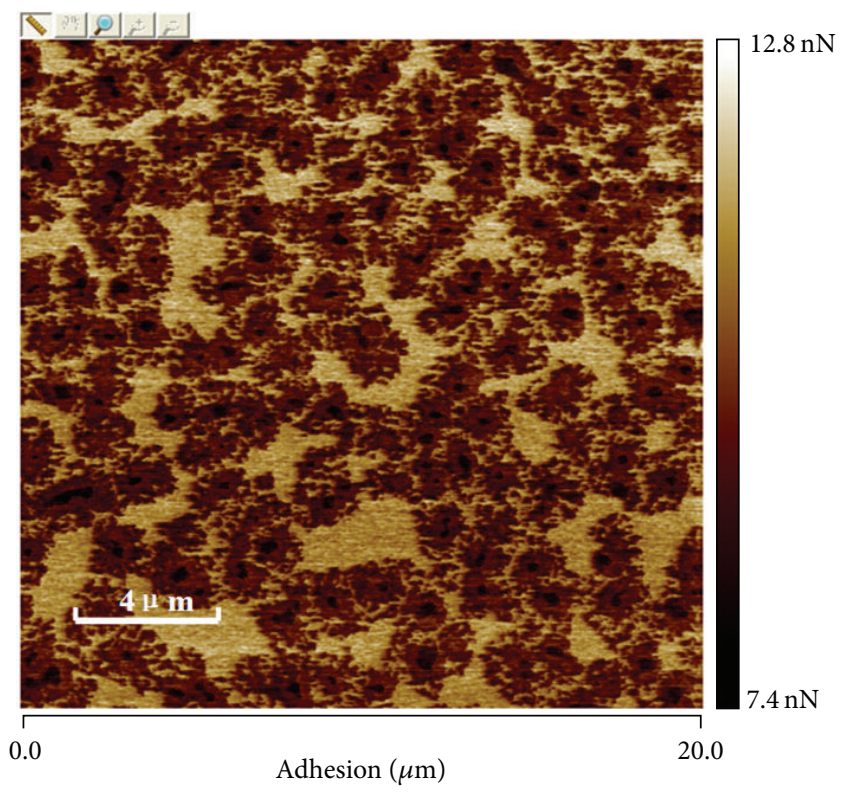

FIgURE 4: Nanoadhesion of asphalt.

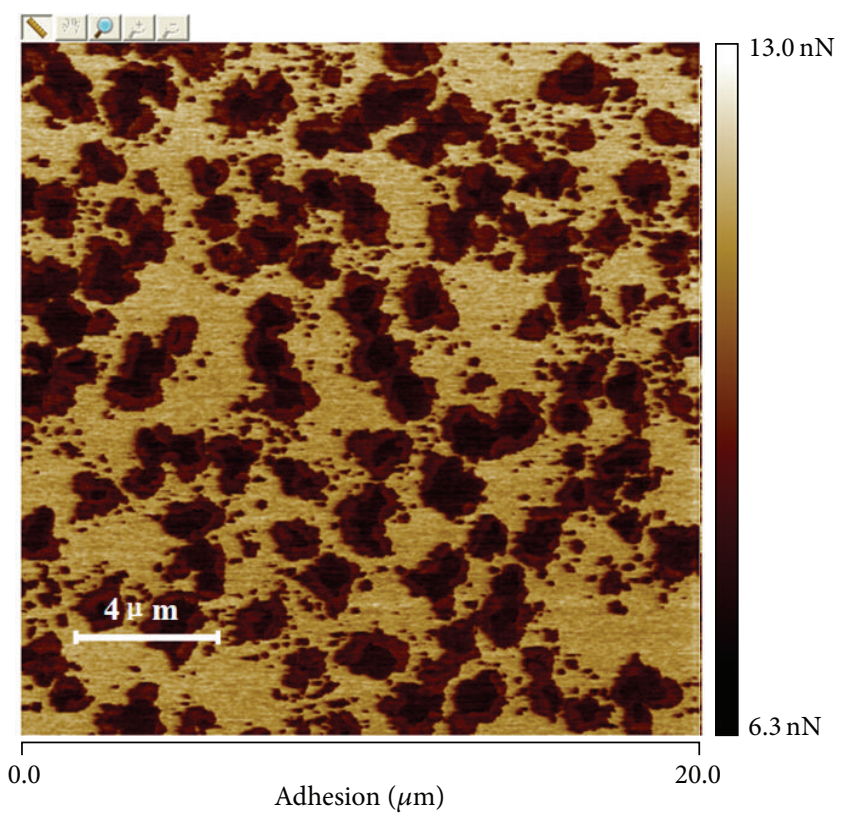

FIGURE 5: Nanoadhesion of RTFO residual.

color area was increased after RTFO aging, indicating that the whole area of adhesion was increased.

Figures 6 and 7 are the nanoforces curves of the binder before and after aging, a typical result taken from asphalt; both had the same trend. Here are the exploration and explanation for Figure 6. A nanoforce curve result can be divided into two parts-engagement part (curve A, abscissa from right to left), retraction part (curve $\mathrm{B}$, abscissa from left to right). Curve $A$ is characterization of the process that needle got closing to the sample, concave valley of curve A was caused by the van der waals force (2part) between probe and sample molecules, it mainly showed the attraction force 


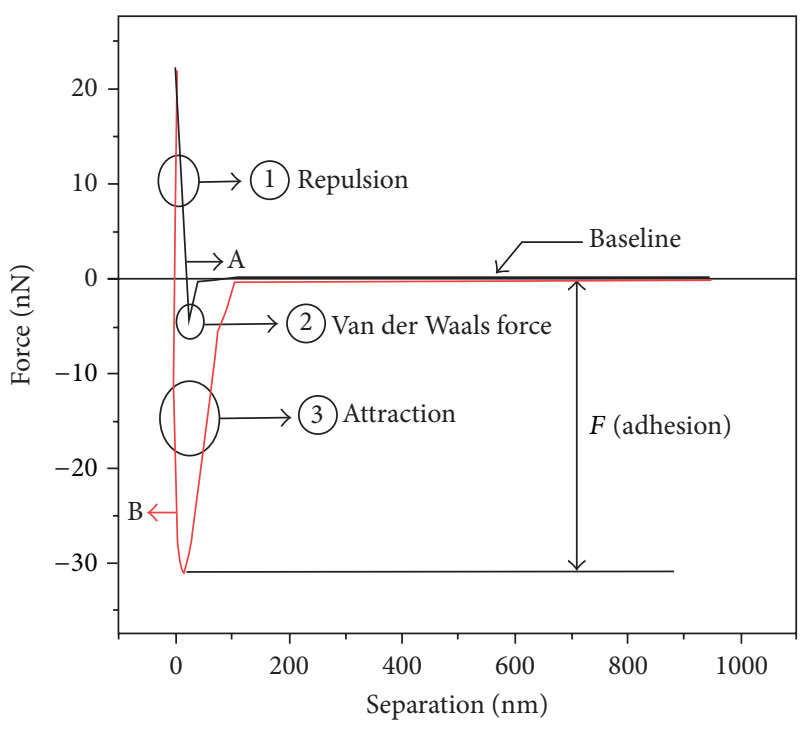

FIGURE 6: Nanoforce of asphalt.

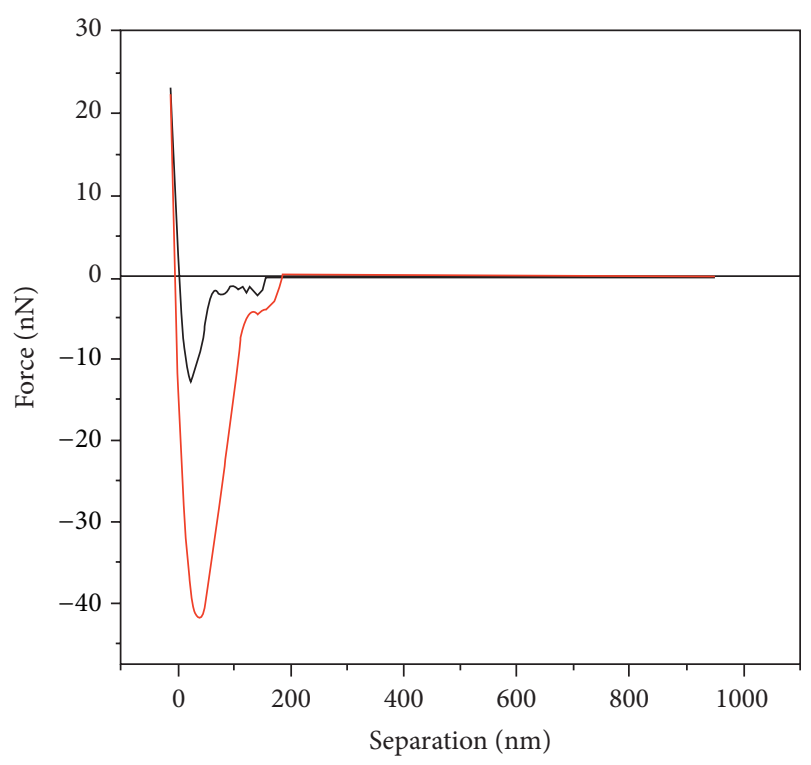

FIGURE 7: Nanoforce of asphalt RTFO residual.

at this time. As the probe kept getting close to the sample, the nanorepulsive force between tip and sample increased (1) part represented repulsion part above the baseline). When the nanorepulsive force reached the maximum, the distance between the sample and probe became the closest, while the probe began to retract, that is, leaving the sample. Curve B in Figure 6 showed that the probe began to leave the sample (3)part represented attraction part below the baseline). The adhesion of the sample can be reflected by the difference between the lowest point of retract part of the force curve (Curve B) and the baseline. The lowest point meant the largest attraction when the probe retracted out in the process of the sample of the binder sample. The point was often used to reflect the information of binding force of the asphalt binder sample. Work of adhesion is associated with the energy
TABLE 2: Adhesion force of different asphalt aging stage.

\begin{tabular}{lc}
\hline Degree of aging & $\begin{array}{c}\text { Adhesion force of asphalt } \\
(\mathrm{nN})\end{array}$ \\
\hline Original & 30.7 \\
RTFO residual & 41.5 \\
\hline
\end{tabular}

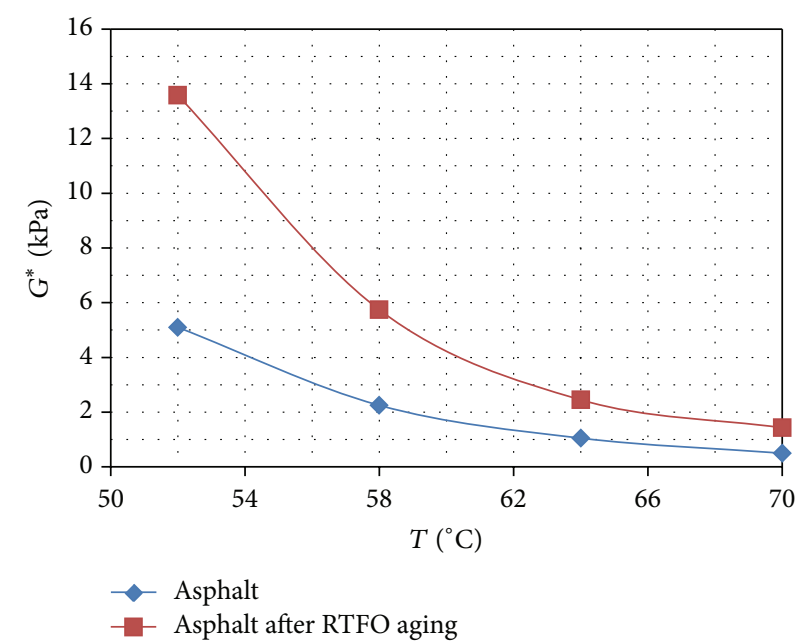

FIGURE 8: $G^{*}$, temperature of asphalt before and after RTFO aging.

necessary to promote adherence. The behavior of the work of adhesion is similar to that observed for the adhesive force [10]. In principle, the value of separation cannot be negative, which was negative in some of Figures 4-7. The reason may be caused by the overloaded ramp force that can be solved by reducing the value of trigger threshold during the process of AFM experiment.

Figures 6 and 7 indicated that the adhesion can be reflected by retraction of nanoforce curve (i.e., the difference between the lowest part of the valley in the force curve B and the baseline). The point of valley means the largest attraction at the process of probe exiting samples. After that point, the probe can get rid of attraction and the force curve reaches the baseline. It can be seen from Table 2 that the adhesion values were $30.7 \mathrm{nN}$ and $41.5 \mathrm{nN}$ for asphalt and RTFO residuals, respectively. Adhesion force increased after RTFO aging.

3.2. Rheological Results from DSR. DSR measured rheological properties of asphalt before and after aging under temperatures from $52^{\circ} \mathrm{C}$ to $70^{\circ} \mathrm{C}$, respectively, in accordance with the American AASHTOTP-93 requirements. DSR test results of asphalt are shown in Table 3. The relationship of different temperatures with $G^{*}, G_{1}, G_{2}$, and $G^{*} / \sin (\delta)$ was shown in Figures $8,9,10$, and 11 , and respectively.

Figures $8,9,10$, and 11 presented the complex shear modulus $G^{*}$, elastic modulus $G_{1}$, viscous modulus $G_{2}$, and $G^{*} / \sin (\delta)$ of asphalt binders before and after RTFO aging. The greater the $G^{*} / \sin (\delta)$, a rutting factor, the better the asphalt material resistant to high temperature deformation. A higher $G^{*}$ value indicates that the asphalt binder has higher stiffness to resist rutting, and low phase angle $(\delta)$ 
TABLE 3: Rheological properties of asphalt before and after RTFO tests.

\begin{tabular}{|c|c|c|c|}
\hline Test project & Test temperature $/{ }^{\circ} \mathrm{C}$ & Asphalt & RTFO aged asphalt residual \\
\hline \multirow{4}{*}{$G^{*} / \sin (\delta)(\mathrm{KPa})$} & 52 & 5.10 & 13.70 \\
\hline & 58 & 2.25 & 5.77 \\
\hline & 64 & 1.05 & 2.46 \\
\hline & 70 & 0.50 & 1.44 \\
\hline \multirow{4}{*}{ Phase angle $\left(^{\circ}\right)$} & 52 & 85.8 & 82.5 \\
\hline & 58 & 86.7 & 84.5 \\
\hline & 64 & 87.2 & 86 \\
\hline & 70 & 86.3 & 84.4 \\
\hline \multirow{4}{*}{$G^{*}(\mathrm{KPa})$} & 52 & 5.10 & 13.58 \\
\hline & 58 & 2.25 & 5.74 \\
\hline & 64 & 1.05 & 2.45 \\
\hline & 70 & 0.50 & 1.43 \\
\hline \multirow{4}{*}{ Elastic $G_{1}(\mathrm{KPa})$} & 52 & 0.37 & 1.77 \\
\hline & 58 & 0.13 & 0.55 \\
\hline & 64 & 0.05 & 0.17 \\
\hline & 70 & 0.03 & 0.14 \\
\hline \multirow{4}{*}{ Viscous $G_{2}(\mathrm{KPa})$} & 52 & 5.09 & 13.47 \\
\hline & 58 & 2.25 & 5.72 \\
\hline & 64 & 1.05 & 2.45 \\
\hline & 70 & 0.50 & 1.43 \\
\hline
\end{tabular}

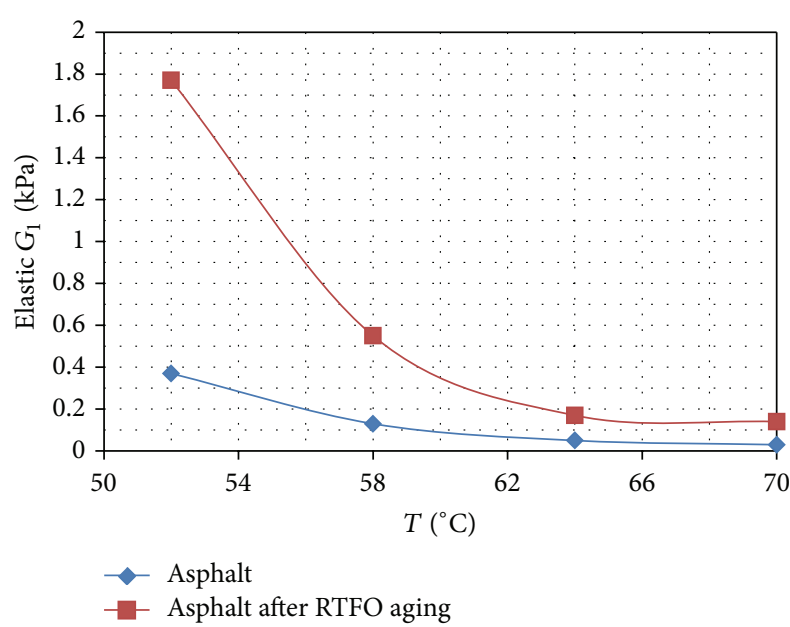

FIGURE 9: $G_{1}$, temperature of asphalt before and after RTFO aging.

value ensures that the asphalt becomes more elastic to recover part of deformation [11]. Overall, the $G^{*}$ decreased as the testing temperature increased for both the original and RTFO residual. Moreover, $G^{*}$ of the asphalt after RTFO had a higher value than that of the original. However, the difference between the $G^{*}$ of RTFO residual and that of the original one decreased as the temperature increased; see Figure 8. It can be concluded that RTFO aging had much more influence on the $G^{*}$ when the temperature is low. The $G_{1}, G_{2}$, and $G^{*} / \sin (\delta)$ changed with the temperature in a similar way to that of $G^{*}$; that is, the trend of the change of $G^{*}$ with the temperature

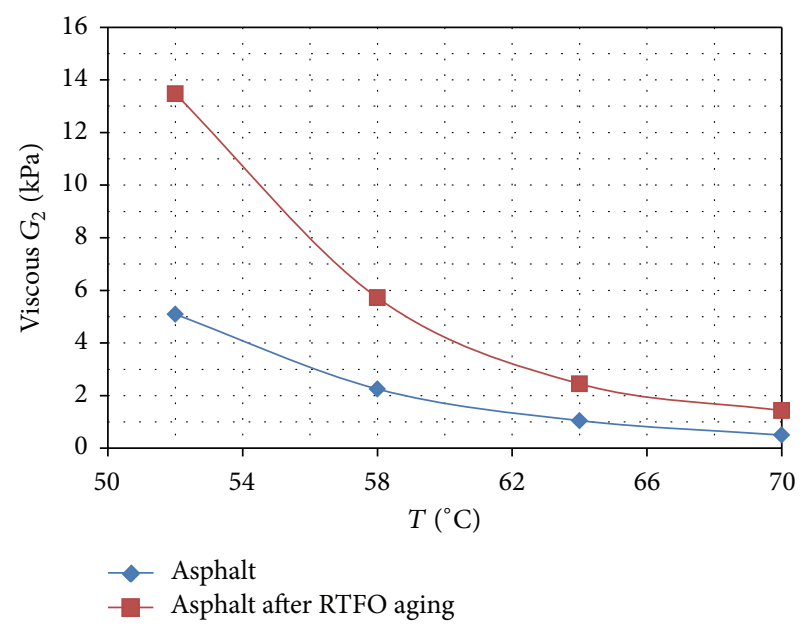

FIGURE 10: $G_{2}$, temperature of asphalt before and after RTFO aging.

is true for the other properties presented (see Figures 8-11 again).

Apparent changes in viscoelastic properties (e.g., $G^{*}$, $\left.G^{*} \sin (\delta)\right)$ with number of cycles of loading are used to define fatigue performance of asphalt binder. However, the mechanisms responsible for apparent changes in these viscoelastic properties were previously not well understood [12]; it is necessary to make further study of micromechanical mechanism of asphalt binders. Nanoadhesion of the asphalt binder from both the image figure and curve was higher for RTFO residual than the original one. This was consistent with the increase of $G^{*}$ of the binder before and after RTFO aging. 


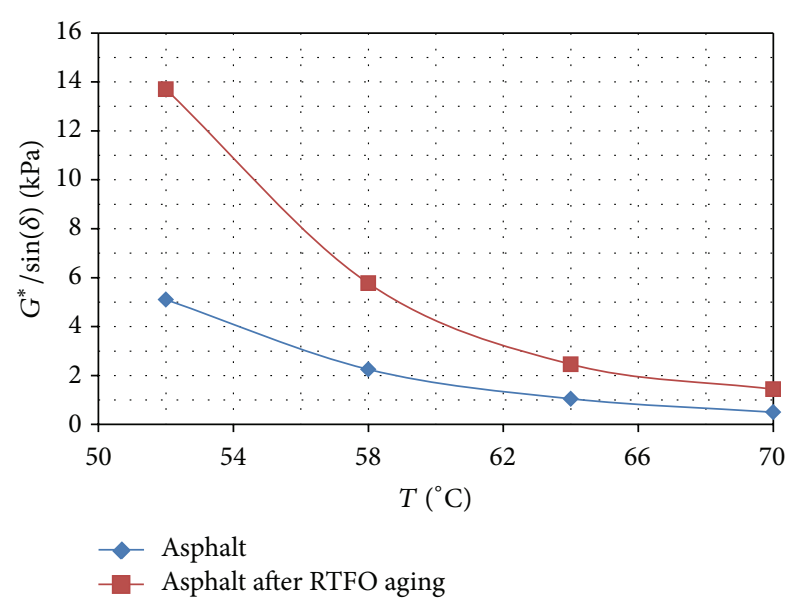

FIGURE 11: $G^{*} / \sin (\delta)$, temperature of asphalt before and after RTFO aging.

\section{Summary and Conclusions}

In the study, the changes in nanomechanical properties were measured on base binder of both original and RTFO residuals using atomic force microscope (AFM), and the rheological properties were tested by dynamic shear rheometer (DSR). Conclusions can be drawn as follows:

(1) The nanoadhesion was successfully measured from AFM of the picture and curve and it was found that it increased after RTFO aging for base binders. Nanoforce curve from AFM showed that adhesion force is $30.7 \mathrm{nN}$ and $41.5 \mathrm{nN}$ for asphalt and RTFO residuals, respectively.

(2) $G^{*}$ of the binders was higher for RTFO residual than for the original one. The influence between the $G^{*}$ of the RTFO residual and that of the original was temperature-dependent and decreased as the temperature increased.

(3) The rheological properties of the asphalt changed consistently with the nanomechanical properties with the aging.

(4) From the tests of AFM and RTFO, the results had a good correlation of base asphalt with the aging; SBS modified asphalt and other asphalt with different modifying agents should be tested in the future study to understand the aging mechanism of different asphalt better.

\section{Conflict of Interests}

The authors declare that there is no conflict of interests regarding the publication of this paper.

\section{Acknowledgment}

This research was supported financially by Chinese National Science Foundation with Grant no. 51378328.

\section{References}

[1] C. Joshi, A. Patted, M. R. Archana, and M. S. Amarnath, "Determining the rheological properties of asphalt binder using dynamic shear rheometer (DSR) for selected pavement stretches," International Journal of Research in Engineering and Technology, no. 11, pp. 192-196, 2013.

[2] D.-W. Cho and H. U. Bahia, "New parameter to evaluate moisture damage of asphalt-aggregate bond in using dynamic shear rheometer," Journal of Materials in Civil Engineering, vol. 22, no. 3, pp. 267-276, 2010.

[3] C. M. Johnson, H. U. Bahia, and H. Wen, "Evaluation of strain-controlled asphalt binder fatigue testing in the dynamic shear rheometer," in Proceedings of the 4th International SIIV Congress, pp. 1-11, Palermo, Italy, 2007.

[4] T. R. Hoare and S. A. M. Hesp, "Low-temperature fracture testing of asphalt binders," Transporation Research Record, vol. 1782, pp. 36-42, 2000.

[5] D. A. Anderson, L. Lapalu, M. O. Marasteanu, Y. M. Le Hir, J.-P. Planche, and D. Martin, "Low-temperature thermal cracking of asphalt binders as ranked by strength and fracture properties," Transportation Research Record, vol. 1766, no. 1, pp. 1-6, 2001.

[6] F. Olard and H. Di Benedetto, "Fracture toughness and fracture energy of bituminous binders at low temperature," in Proceedings of the 5th International RILEM Conference on Reflective Cracking in Pavements, vol. 37, pp. 359-366, Limoges, France, May 2004.

[7] B. McCarron, X. Yu, and M. Tao, The Investigation of "BeeStructures" in Asphalt Binders, Department of Physics, Worcester Polytechnic Institute, 2011.

[8] T. Khedaywi, G. Al-Khateeb, and M. Irfaeya, "Effect of medical ash on shear properties of asphalt binder using superpave dynamic shear rheometer (DSR)," Journal of Solid Waste Technology and Management, vol. 38, no. 1, pp. 19-27, 2012.

[9] R. G. Allen, D. N. Little, and A. Bhasin, "Structural characterization of micromechanical properties in asphalt using atomic force microscopy," Journal of Materials in Civil Engineering, vol. 24, no. 10, pp. 1317-1327, 2012.

[10] E. R. Dourado, R. A. Simao, and L. F. M. Leite, "Mechanical properties of asphalt binders evaluated by atomic force microscopy," Journal of Microscopy, vol. 245, no. 2, pp. 119-128, 2012.

[11] G. G. Al-Khateeb and K. Z. Ramadan, "Investigation of the effect of rubber on rheological properties of asphalt binders using superpave DSR," KSCE Journal of Civil Engineering, vol. 19, no. 1, pp. 127-135, 2015.

[12] C. Hintz and H. Bahia, "Understanding mechanisms leading to asphalt binder fatigue in the dynamic shear rheometer," Road Materials and Pavement Design, vol. 14, supplement 2, pp. 231251, 2013. 

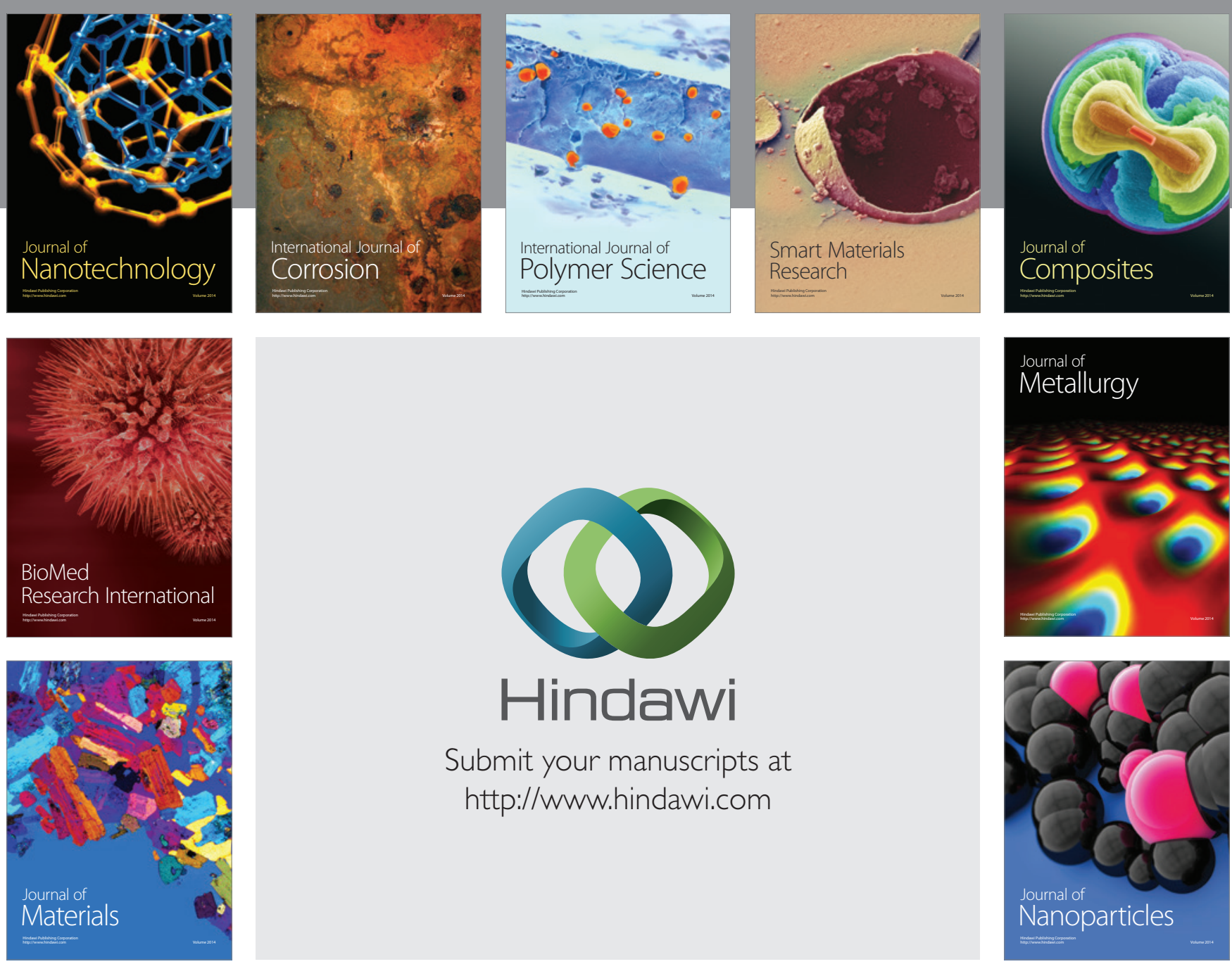

Submit your manuscripts at http://www.hindawi.com
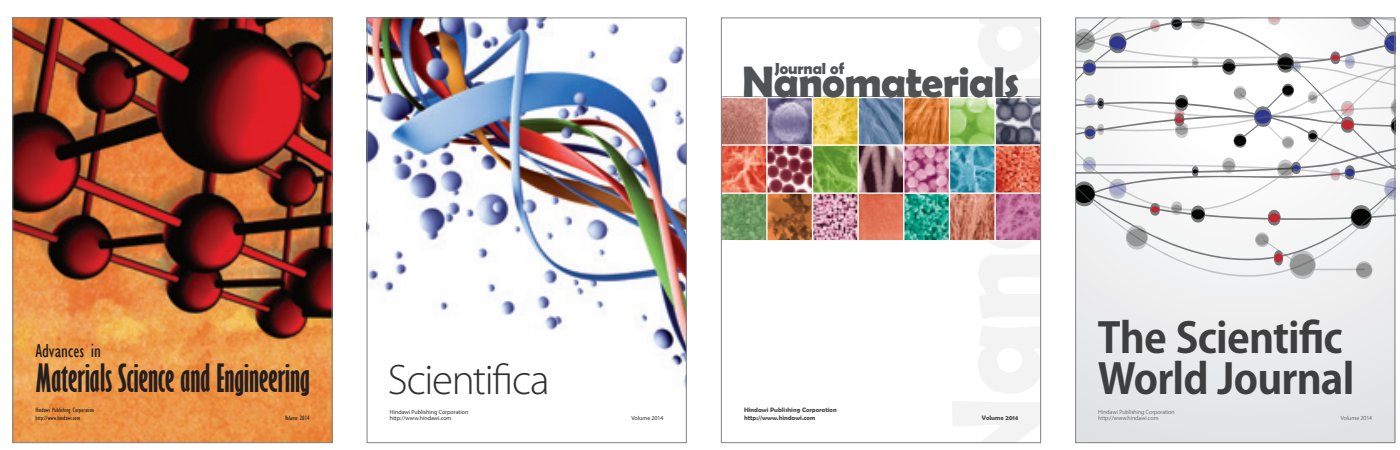

\section{The Scientific World Journal}
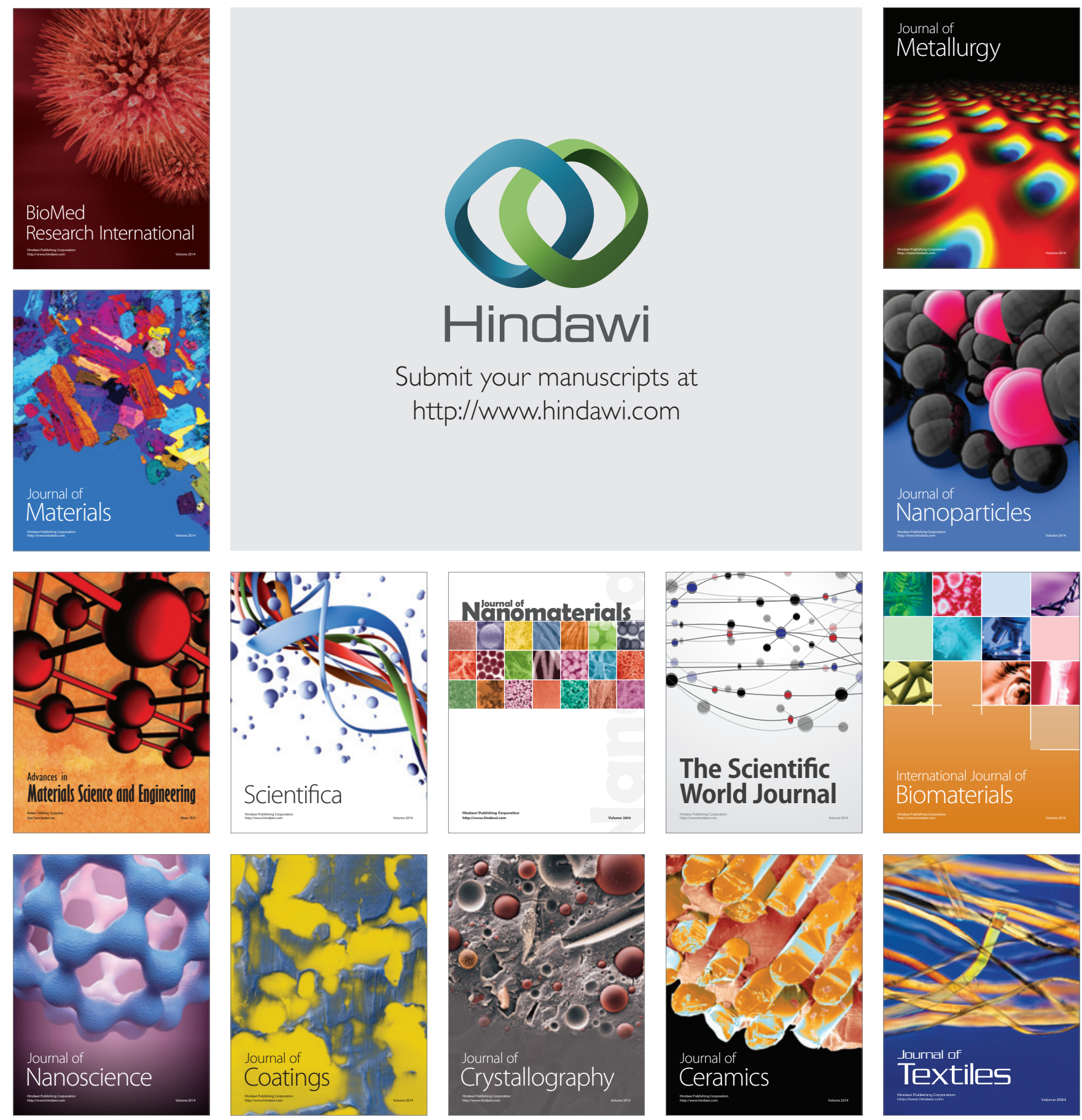